\title{
AVALIAÇÃO DO POTENCIAL FOTOPROTETOR DOS ÓLEOS ESSENCIAIS E EXTRATOS ETANÓLICOS DE Aniba canelilla (H.B.K) Mez.
}

\author{
E.Q. da FONSECA Jr ${ }^{1}$, R.B. de CASTILHO ${ }^{2}$ e G.F. da SILVA ${ }^{1,2}$ \\ ${ }^{1}$ Universidade do Estado do Amazonas, Faculdade de Engenharia Química \\ 2 Universidade Federal do Amazonas, Departamento de Pós-Graduação em Química \\ E-mail para contato: edsonfonsecaqueiroz@gmail.com
}

\begin{abstract}
RESUMO - O protetor solar é uma loção que ajuda a proteger a pele da radiação ultravioleta do sol. Assim, há dois tipos de filtros solares; os químicos (protetores solares) que absorvem a radiação UV antes de penetrar nas camadas da pele; e os físicos (bloqueadores solares) que refletem e espalham esse tipo de radiação. Dessa maneira, o presente trabalho teve como objetivo avaliar a atividade fotoprotetora dos óleos essenciais e extratos de Aniba canelilla, fazendo o uso do método espectrofotométrico de Mansur; também foi realizada uma triagem fitoquímica qualitativa preliminar para determinar a presença de polifenóis e alcaloides, compostos característicos de plantas que absorvem a radiação UV. $\mathrm{Na}$ concentração utilizada e padronizada, o extrato bruto das folhas foi o que apresentou maior FPS, sendo assim será realizado um estudo mais detalhado em relação a sua composição química para que seus constituintes possam ser isolados e identificados para posteriormente serem empregados em formulações de filtro solar.
\end{abstract}

\section{INTRODUÇÃO}

As radiações solares além de proporcionar saúde e bem estar ao homem, também podem ocasionar danos agudos ou crônicos à pele humana, dependendo da duração e frequência de exposição. De acordo com o Instituto Nacional de Câncer (INCA), o câncer de pele ocupa o primeiro lugar dentre todos os tumores malignos registrados no Brasil (Balogh et al., 2011). Por essa razão, o uso de filtros solares tem sido indicado como uma profilaxia contra os raios ultravioletas (Urbach, 2001).

Atualmente, devida à ação fotoprotetora, muitos extratos e óleos de plantas têm sido empregados em produtos cosméticos como protetores solares. Porém, os mesmos devem apresentar moléculas com estruturas semelhantes às dos filtros sintéticos.

Conforme descrito nas literaturas, realizou-se uma análise fitoquímica qualitativa preliminar para a identificação de alcaloides, flavonoides e taninos. Segundo Henrique et al. (2000), os alcaloides são metabólitos com núcleos aromáticos que agem como absorvedores da radiação ultravioleta. De acordo com Santana et al. (2001), a presença de taninos na planta identifica um potencial na absorção da radiação UV. E o espectro de absorção dos flavonoides 


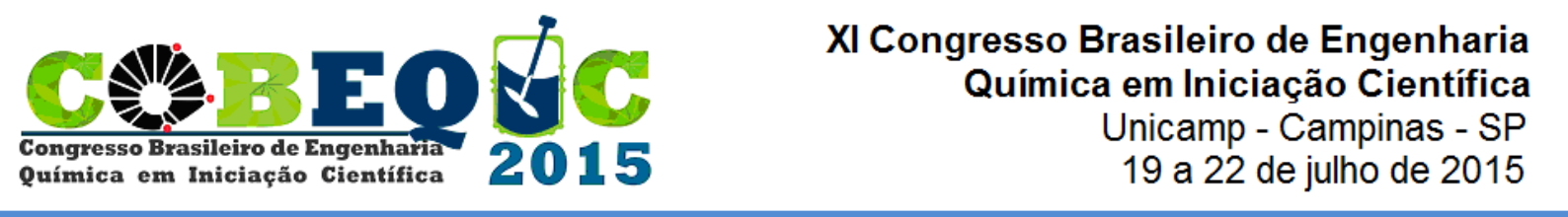

quando dispersos em etanol e metanol mostra-se com dois picos, sendo um entre 240 a $280 \mathrm{~nm}$ e o outro nos comprimentos de 300 a 500nm (Bobin et al., 1994).

Assim, como a família Lauracea possui grande importância econômica para região, tanto no uso da madeira e na medicina popular, mas com estudos químicos e farmacológicos escassos (Silva, 2012), propõe-se, neste trabalho, avaliar o potencial fotoprotetor dos extratos etanólicos e óleo essencial de uma de suas espécies (Aniba canelilla) e estimar esse efeito na região do UVA relacionando com o FPS obtido de UVB.

\section{MATERIAIS E MÉTODOS}

\subsection{Coleta do Material Vegetal}

As folhas e galhos foram coletados no período chuvoso (abril de 2011) na Reserva Florestal Adolpho Ducke do Instituto Nacional de Pesquisas da Amazônia - INPA, no município de Manaus, Amazonas, no período matutino. Eles foram obtidos de onze árvores de Aniba canelilla, dos quais o material vegetal de dez árvores foi utilizado para obtenção do óleo essencial e de uma árvore, devidamente identificada, foram obtidos os extratos etanólicos.

\subsection{Obtenção dos Extratos Etanólicos de Folhas e Galhos de Aniba canelilla.}

O material vegetal foi seco à sombra em temperatura ambiente e local arejado durante dez dias e após este período foi triturado em moinho elétrico de facas com tela de $3 \mathrm{~mm}$. $\mathrm{O}$ material foi macerado à frio em álcool etílico de cereais $\left(92,8^{\circ}\right.$ INPM) por 72 horas à temperatura ambiente, filtrando-os em seguida e adicionando um novo solvente para uma nova maceração por mais 72 horas e passando por uma nova filtragem, totalizando um período de nove dias. $\mathrm{O}$ filtrado foi submetido à evaporação lenta, sob pressão reduzida, à temperatura de $45{ }^{\circ} \mathrm{C}$, no aparelho evaporador rotativo. $\mathrm{O}$ extrato bruto foi submetido à partição líquido-líquido, empregando primeiro o solvente $n$-hexano, e segundo, o diclorometano. Assim, resultaram uma fase solúvel em $n$-hexano e uma em diclorometano, que passaram pelo evaporador rotativo sob pressão reduzida a $40{ }^{\circ} \mathrm{C}$ para a retirada do solvente, restando ainda uma fase hidroalcoólica que foi liofilizada.

\subsection{Obtenção dos Óleos Essenciais.}

Os óleos essenciais de folhas e galhos foram obtidos por arraste a vapor em aparelho tipo Clevenger modificado, onde 100 gramas do material vegetal foram destilados com 1000 gramas de água destilada a temperatura de $100{ }^{\circ} \mathrm{C}$ durante três horas e trinta minutos para folhas e seis horas para galhos.

\subsection{Análise Fitoquímica Qualitativa Preliminar.}

Foi realizada uma avaliaçao fitoquímica (testes para alcaloides, flavonoides e taninos) através de um processo de prospecção qualitativa (Matos, 1997). 


\subsection{Determinação do Fator de Proteção Solar (FPS).}

O FPS foi determinado pelo método espectrofotométrico desenvolvido por Mansur et al. (1986), onde foram feitas soluções dos óleos essenciais e extratos etanólico e hidroalcoólico de Aniba canelilla na concentração de 1\% (m/v) seguidas de diluições para análise. As soluções de óleos e extratos foram preparadas com isopropanol e etanol, respectivamente, e assim, realizou-se uma varredura entre os comprimentos de onda de 280 a 400nm (Espectrofotômetro Shimadzu, modelo UV-1800) em cubeta de quartzo de 1,0 cm de caminho óptico; resultando numa concentração de $0,1 \%$. As absorbâncias obtidas foram utilizadas para o cálculo do FPS in vitro e também necessárias para a elaboração dos espectros de absorção. Além disso, determinou-se a razão UVA/UVB a fim de conhecer sua proteção em relação à radiação UVA, proposta por Boot the Chemist Limited. Seus resultados são expostos com estrelas, sendo o maior número correspondente a uma maior proteção UVA estimada.

\section{RESULTADOS E DISCURSSÃO}

Os valores resultantes do procedimento da atividade fotoprotetora podem ser observados na Tabela 1.

Tabela 1 - Valores do FPS e razão UVA/UVB calculados para cada extrato, óleo, protetor comercial e filtro químico

\begin{tabular}{lcc}
\hline Amostras & FPS & Razão UVA/UVB \\
\hline FHDF & 41,43 & 1,04 \\
FETG & 34,83 & 0,87 \\
FETF & 90,25 & 1,64 \\
OEG & 6,93 & 0,33 \\
OEF & 14,08 & 0,62 \\
FC & 72,08 & 1,48 \\
QUER & 26,12 & - \\
\hline
\end{tabular}

FHDF=Fase Hidroalcoólica Folhas; FETG=Fase Etanólica Galhos; FETF=Fase Etanólica Folhas; OEG=Oleo Essencial Galhos; $\mathrm{OEF}=$ Oleo Essencial Folhas; FC=Filtro Comercial; QUER=Quercetina.

De acordo com os dados da Tabela 1, os extratos absorveram de maneira favorável a radiação UV em comparação com o padrão. Segundo a revista Boots the Chemists (2004), os extratos hidroalcoólico e bruto das folhas de $A$. canelilla apresentaram uma ultra proteção na região do UVA, enquanto os demais apresentaram uma moderada proteção contra o UVA. Dessa maneira, a metodologia aplicada nesse estudo apresenta uma boa correlação com os testes in vivo, o que garante a confiabilidade dos resultados. A Figura 1 apresenta a curva de espectros de absorção dos óleos e extratos de Aniba canelilla, na mesma concentração. 
Figura 1 - Espectros de absorção dos extratos e óleos de Aniba canelilla e dois padrões para um controle.

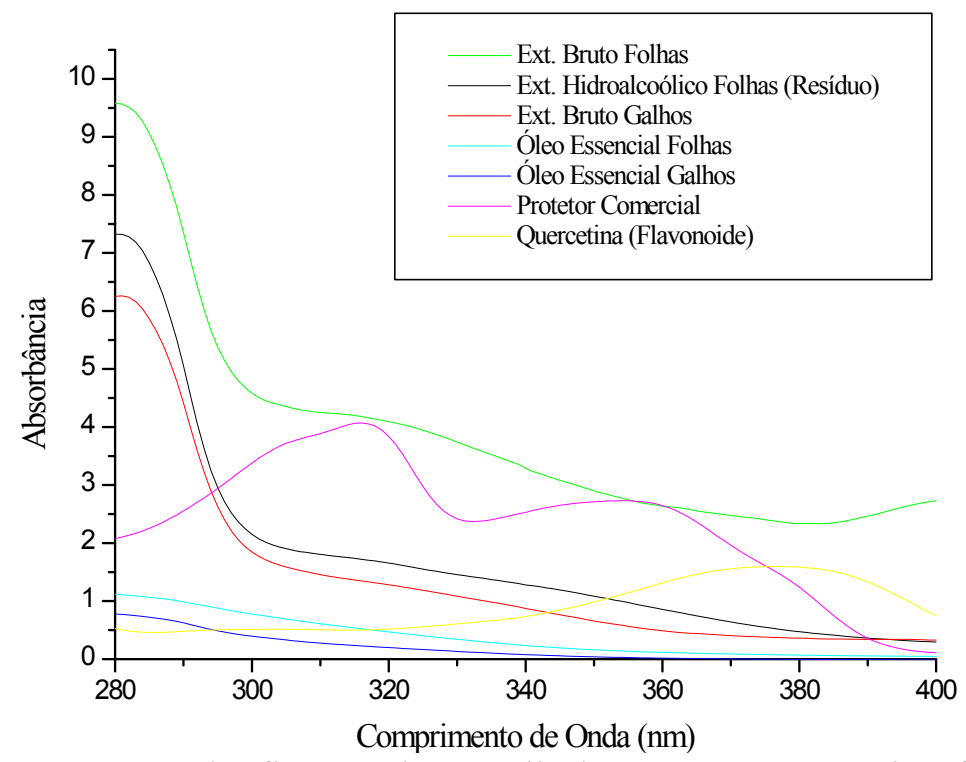

De acordo com o estudo fitoquímico preliminar, os extratos das folhas e galhos de Aniba canelilla demonstraram a presença de flavonoides, o qual segundo Bobin et al. (1994) apresenta seu espectro de absorção tipicamente com dois picos, sendo um na faixa de 240 a $280 \mathrm{~nm}$ e outro nos comprimentos de 300 a 500nm, quando dispersos em etanol. Assim, segundo Silverstein et al. (2005), os picos presentes no espectro do extrato bruto das folhas, obtido com maior caráter fotoprotetor, representam transições que envolvem combinações de níveis vibracionais e rotacionais do estado fundamental e uma combinação correspondente no nível eletrônico excitado. Deste modo, quando a molécula absorve luz em seu comprimento de onda mais longo, um elétron é excitado do seu orbital ocupado de maior energia para o seu orbital vazio de menor energia. Portanto, os extratos de Aniba canelilla podem apresentar compostos, como flavonoides, cujas moléculas apresentam ligações conjugadas que possuem absorção máxima em comprimentos de onda maiores de $200 \mathrm{~nm}$, pois as flavonas e flavonóis oxigenados em seu anel-A apresentam uma alta intensidade na banda entre $240-285 \mathrm{~nm}$ e uma fraca intensidade na região $300-550 \mathrm{~nm}$, quando analisados no UV/Vis. Sendo assim, o espectro no UV desses flavonoides assemelham-se bastante com o extrato bruto da folhas, confirmando a presença desses na planta da família Lauraceae.

\section{CONCLUSÃO}

Os resultados obtidos demonstraram que, na concentração utilizada, o extrato bruto das folhas apresentou-se o mais eficiente comparado ao protetor comercial. Portanto, será realizado um estudo mais aprofundado em relação a sua composição química para que os constituintes responsáveis por essa atividade possam ser analisados. Visto que, de acordo com a legislação brasileira, RDC $N^{\circ} 30$ de $1^{\circ}$ de Junho de 2012 (Brasil, 2012), um produto para ser utilizado em cosméticos fotoprotetores, deve apresentar FPS no mínimo 6. Dessa forma, extratos etanólicos de Aniba canelilla mostram-se promissoras quanto sua utilização em formulações fotoprotetoras de acordo com o método avaliado. 


\section{REFERÊNCIAS}

BALOGH, T. S.; PEDRIALI, C. A.; BABY, A. R.; VELASCO, M. V. R.; KANEKO, T. M. Ultraviolet radiation protection: current available resoucers in photoprotection. $A$. Brasil. de Dermat., v. 86, p. 732-742, 2011.

BOBIN, M. F.; RAYMOND, M.; MARTINI, M. C. UVA/UVB absorption properties of natural products. Cosm. Toilet., v. 109, p. 63-78, 1994.

BOOTS THE CHEMISTS Ltd. (England). The Revised guidelines to the practical measurement of UVA: UVB ratios according to the boots star rating system. Nottingham: The Boots CO PLC, 2004.

HENRIQUE, A. T.; KERBER, V. A.; MORENO, P. R. H. Alcalóides: generalidades e aspectos básicos. UFRGS/UFSC: Porto Alegre/Florianópolis., p. 641-642, 2000.

MANSUR, J. de. S.; BREDER, M. V.R; MANSUR, M. C. A.; AZULEY, R. D. Determinação do fator de proteção solar por espectrofotometria. A. Brasil. de Dermat., v. 61, p. 167$172,1986$.

MATOS, F. J. A. Introdução à fitoquímica experimental. Fortaleza: Editora EUFC, 1997.

SANTANA, J. L.; PEÑA, M.; MARTINEZ, F.; GÓMEZ, A.; CORDONÍO, E.; GARCIA, O.; GARCIA, G.; VARGAS, L.M.; GARCIA, M.; GARCIA, C. Evaluación de la actividad antimicrobiana, fotoprotectora, antielastasa y antioxidante de polifenois de origen natural, empleados wen formulaciones cosméticas. XV Congr. Lat. Ameri. e Ibér. de Quím. Cosmét. Buenos Aires, Argentina.

SILVA, G. F. da. Estudo do potencial biotecnológico de Aniba canelilla para obtenção de cosméticos. Dissertação de mestrado. ESA. Univ. Est. Amaz. 2012.

SILVERSTEIN, R. M; BASSLER, G. C.; MORRILL, T. C. Identificação dos compostos orgânicos. Rio de Janeiro: Guanabara Koogan, 1994.

URBACH, F. The historical aspects of sunscreens. J. Photochem. Photobio. B: Biol., v. 64, p. 99-104, 2001. 